\title{
Elastic-Plastic and Inelastic Characteristics of High Strength Steel Sheets under Biaxial Loading and Unloading
}

\author{
Mohammad Omar ANDAR, ${ }^{1)}$ Toshihiko KUWABARA, ${ }^{2)}$ Shigeru YONEMURA ${ }^{3)}$ and Akihiro UENISHI) \\ 1) Department of Mechanical Systems Engineering, Graduate School of Technology, Tokyo University of Agriculture and \\ Technology, 2-24-16 Naka-cho, Koganei, Tokyo 184-8588 Japan. E-mail: andaromar@gmail.com \\ 2) Division of Advanced Mechanical Systems Engineering, Institute of Symbiotic Science and Technology, Graduate School \\ of Tokyo University of Agriculture and Technology, 2-24-16 Nakacho, Koganei Tokyo 184-8588 Japan. \\ E-mail: kuwabara@cc.tuat.ac.jp $\quad 3)$ Kimitsu R\&D Laboratory, Nippon Steel Corporation, 1 Kimitsu, Kimitsu, Chiba 299- \\ 1141 Japan. E-mail: yonemura.shigeru@nsc.co.jp, uenishi.akihiro@nsc.co.jp
}

(Received on October 23, 2009; accepted on February 5, 2010)

\begin{abstract}
Biaxial tensile tests followed by biaxial unloading and reloading are carried out for BH340 and DP590 steel alloys. The contours of plastic work and the directions of plastic strain rates were measured at different levels of plastic work in the first and second quadrants of stress space. The applicability of conventional anisotropic yield functions, Hill's quadratic function and the Yld2000-2d function to the accurate prediction of the plastic deformation behavior of these steel alloys is discussed using the measured data. The measured work contours and directions of plastic strain rates were in good agreement with those calculated using the Yld2000-2d yield function with an exponent of four. The initial and subsequent elastic moduli after prestraining and the instantaneous tangent moduli during subsequent unloading after an equivalent plastic prestrain of $\varepsilon_{0}^{\mathrm{p}}=0.02$ are measured from the biaxial loading, unloading and reloading experiments. The moduli of elasticity at reloading were lower by 9 to $17 \%$ than those at initial loading. The amount of strain recovery along the rolling direction (RD) is more than that along the transverse direction (TD) for uniaxial unloading, as well as for biaxial unloading. An exponential decay model is proposed that provides good reproduction of the unloading stress-strain relations, $\left(\sigma / \sigma_{\mathrm{u}}\right)-\Delta \varepsilon /\left(\sigma_{\mathrm{u}} / E_{2}\right)$, of both materials under different stress ratios.
\end{abstract}

KEY WORDS: biaxial tension; contours of plastic work; anisotropic yield function; unloading; inelastic strain recovery; cruciform specimen; instantaneous tangent modulus.

\section{Introduction}

The demand for high strength steel alloys has been increasing due to vehicle weight reduction and crash performance improvement requirements. However, a large springback occurs during the press forming of high strength steel alloys. Springback often causes serious problems in determining the optimum geometry of dies, and is the main impediment to high-efficiency production. In order to establish time- and cost-effective press-forming technologies for automotive body parts requiring the use of high strength steel alloys, it is vital to accurately predict the amount of springback using simulation techniques and determine the optimum forming conditions.

Springback is caused by the bending moment retained in press-formed parts before unloading. ${ }^{1-3)}$ Furthermore, it is also affected by the unloading stress-strain response of the material, i.e., the Bauschinger effect. ${ }^{4-6)}$ Therefore, in order to accurately predict the amount of springback of automotive body parts made from high strength steel alloys, it is crucial to have a highly accurate material model that is capable of predicting the work hardening behavior of the material during biaxial loading, as well as the stress-strain responses during biaxial unloading.
Regarding the measurement of flow stresses under biaxial stress states and the determination of an appropriate anisotropic yield function for a given material, the biaxial tensile testing method with a cruciform specimen is useful. ${ }^{7,8)}$ On the other hand, the development of stresses during unloading of pre-loaded materials has been investigated conventionally for the uniaxial stress state. Some authors have suggested that Young's modulus is decreased with the increase in the amount of prestrain..$^{9-12)}$ Moreover, accurate material modeling of the non-linearity of stress-strain curves during unloading is another important factor for accurate springback simulation. ${ }^{4-6)}$ However, to our knowledge, there has been no experimental work involving the measurement and formulation of the loading and unloading behavior of steel alloy sheets under biaxial stress states.

In this study, the biaxial loading and unloading behavior of two types of steel alloys, a bake-hardenable steel alloy with a tensile strength of $340 \mathrm{MPa}(\mathrm{BH} 340)$ and a dualphase steel alloy with a tensile strength of $590 \mathrm{MPa}$ (DP 590), was precisely measured using biaxial stress tests with cruciform specimens. The effect of pre-loading on the elastic modulus and the inelastic strain recovery behavior for different stress ratios are discussed. An exponential decay model that can well reproduce the unloading stress-strain 
relations of both materials for different stress ratios is proposed.

\section{Experimental Method}

\subsection{Test Materials}

Two types of high strength steel alloy test materials were used in this study: $0.7 \mathrm{~mm}$ thick BH340 and $1 \mathrm{~mm}$ thick DP590. BH and DP denote bake-hardenable and dualphase, respectively. The numbers indicate the tensile strength of the materials. The work hardening characteristics and the $r$-values of the test materials are listed in Table 1.

\subsection{Test Specimens}

Figures 1(a), 1(b) and 1(c) show the geometry of the specimens used in this study. Figure 1(a) is the specimen for the uniaxial tensile test (JIS 13 B-type). Figure 1(b) is the specimen for the biaxial tensile test of sheet metals, which was originally proposed by Kuwabara et al., ${ }^{13)}$ and is the same as those used for the biaxial tensile tests of steel alloys, ${ }^{14-17)}$ aluminum alloys, ${ }^{14,18)}$ austenitic stainless steel SUS304 ${ }^{19)}$ and pure titanium. ${ }^{20)}$ Figure 1(c) is the specimen for the combined tension-compression test of sheet metals, which was originally proposed by Kuwabara et $a l^{21)}$ The $x$ and $y$-axes are in the rolling (RD) and transverse directions (TD) of the materials, respectively. Seven slits have been fabricated in the arms of the specimens at intervals of 7.5 $\mathrm{mm}$ in order to exclude geometric constraint on the $60 \times 60$ mm square gauge section.

The normal strain components, $\varepsilon_{x}$ and $\varepsilon_{y}$, were measured for the specimens shown in Figs. 1(a) and 1(b) using uniaxial strain gauges (Tokyo Sokki Kenkyujo, YFLA-2). A biaxial strain gauge (Tokyo Sokki Kenkyujo, FCA-11-1L) was used at the center of the specimen shown in Fig. 1(c).

\subsection{Testing Apparatus}

Figure 2 shows the biaxial testing apparatus used in this study. It was originally designed and fabricated by Kuwabara et al. ${ }^{13)}$ The hydraulic pressure of each pair of hydraulic cylinders is servo-controlled independently, so that the stress-paths or strain-paths applied to a specimen can be arbitrarily controlled using a closed-loop circuit. The displacements of the rams of the opposing hydraulic cylinders are equalized using the pantograph-type link mechanism proposed by Shiratori and Ikegami, ${ }^{22)}$ so that the centre of the specimen is always maintained at the centre of the testing apparatus during the tests. A load cell is included in each loading direction. Biaxial strain components in the RD and TD of the specimen are measured continuously using strain gauges.

For combined tension-compression tests, the specially designed comb-shaped jig shown in Fig. 3 was used. The comb-shaped jig was originally designed and fabricated by Kuwabara et al. ${ }^{21)}$

\subsection{Procedure for Biaxial Experiments}

The true stress components, $\sigma_{x}$ and $\sigma_{y}$, were determined by dividing the measured loads $F_{x}$ and $F_{y}$ by the current cross-sectional area of the gauge section, which was determined from the measured values of plastic strain compo-
Table 1. Mechanical properties of the test materials.

\begin{tabular}{|c|c|c|c|c|c|c|}
\hline $\begin{array}{c}\text { Test } \\
\text { material }\end{array}$ & $\begin{array}{c}\text { Tensile } \\
\text { direction }\end{array}$ & $\begin{array}{c}\sigma_{0.2} \\
/ \mathrm{MPa}\end{array}$ & $\begin{array}{c}c \\
/ \mathrm{MPa}\end{array}$ & $n^{{ }^{* 1}}$ & $\varepsilon_{0}{ }^{{ }^{1} 1}$ & $r$-value ${ }^{{ }^{2}}$ \\
\hline \multirow{5}{*}{ BH340 } & $0^{\circ}$ & 246 & 595 & 0.216 & 0.013 & 1.52 \\
\cline { 2 - 7 } & $22.5^{\circ}$ & 254 & 600 & 0.213 & 0.015 & 1.33 \\
\cline { 2 - 7 } & $45^{\circ}$ & 264 & 601 & 0.207 & 0.015 & 1.15 \\
\cline { 2 - 7 } & $67.5^{\circ}$ & 265 & 588 & 0.200 & 0.016 & 1.36 \\
\cline { 2 - 7 } & $90^{\circ}$ & 260 & 577 & 0.203 & 0.016 & 1.64 \\
\hline \multirow{5}{*}{ DP590 } & $0^{\circ}$ & 359 & 1157 & 0.251 & 0.007 & 0.85 \\
\cline { 2 - 7 } & $22.5^{\circ}$ & 363 & 1163 & 0.251 & 0.007 & 0.81 \\
\cline { 2 - 7 } & $45^{\circ}$ & 372 & 1152 & 0.243 & 0.007 & 0.84 \\
\cline { 2 - 7 } & $67.5^{\circ}$ & 375 & 1160 & 0.245 & 0.008 & 0.96 \\
\cline { 2 - 7 } & $90^{\circ}$ & 372 & 1167 & 0.247 & 0.008 & 1.02 \\
\hline
\end{tabular}

*1 Approximated using $\sigma=c\left(\varepsilon_{0}+\varepsilon^{\mathrm{p}}\right)^{n}$ for $\varepsilon^{\mathrm{p}}=0.002-0.093$

*2 Measured at nominal uniaxial strain $\varepsilon_{\mathrm{N}}=0.1$
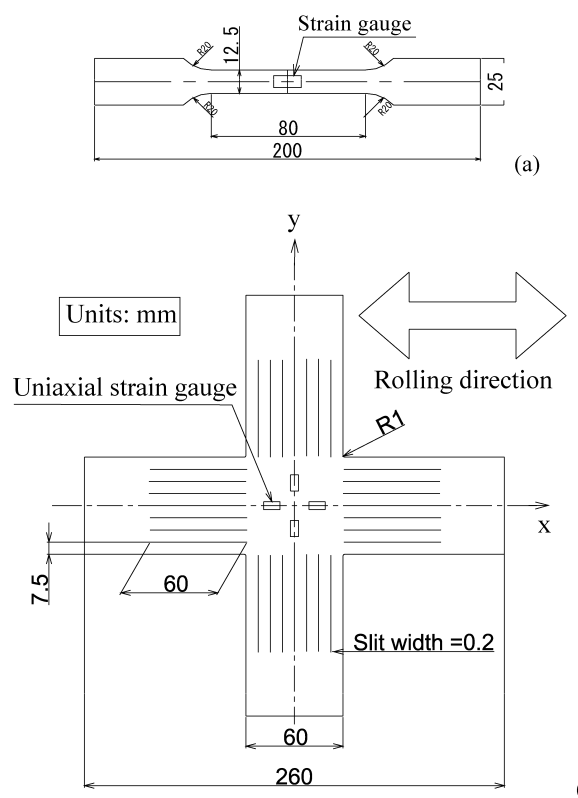

(b)

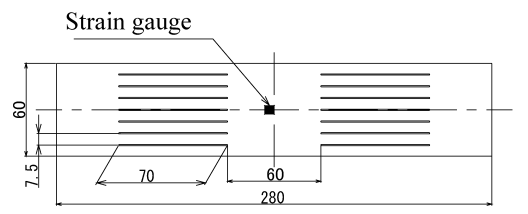

(c)

Fig. 1. Geometry of the specimens used for (a) the uniaxial tensile test (JIS 13 B-type), (b) biaxial tensile test ${ }^{13)}$ and (c) the combined tension-compression test. ${ }^{21)}$

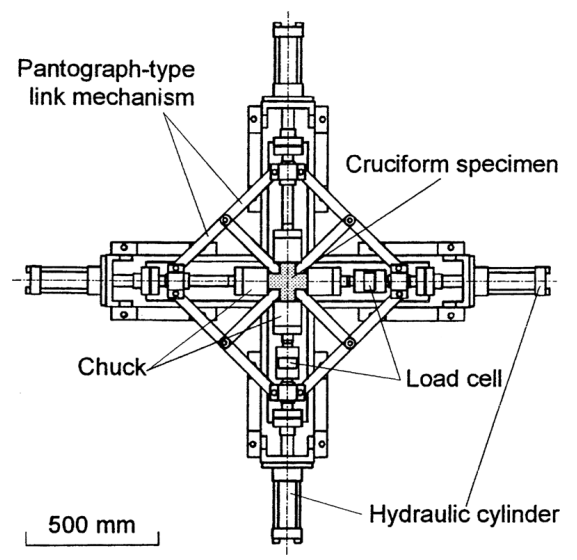

Fig. 2. Experimental apparatus used for the biaxial tensile test. ${ }^{13)}$ 


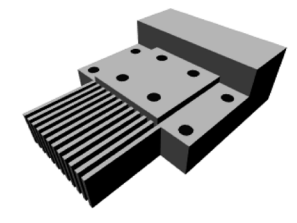

(a)

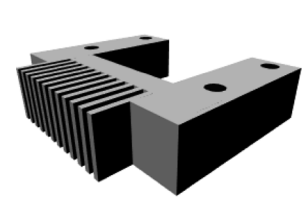

(c)

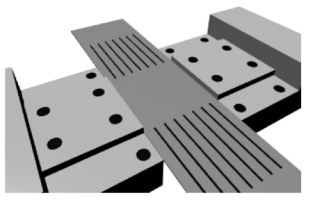

(b)

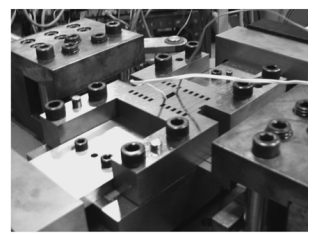

(d)
Fig. 3. Test jigs for combined tension-compression tests. ${ }^{21)}$ (a) Lower die. (b) Specimen placed on the lower die. (c) Upper die. (d) Specimen sandwiched between the lower and upper dies with both ends clamped by the chucks of the biaxial tensile testing machine.

nents, $\varepsilon_{x}^{\mathrm{p}}$ and $\varepsilon_{y}^{\mathrm{p}}$, assuming the condition of constant volume. $\varepsilon_{x}^{\mathrm{p}}$ and $\varepsilon_{y}^{\mathrm{p}}$ were measured on the centerlines of the specimen; therefore, it was assumed that $\sigma_{x y}=0$. Three specimens were tested for one stress ratio for uniaxial tensile tests, 2 for biaxial tensile tests, 2 for combined tensioncompression tests, and 3 for biaxial loading-unloading tests.

\subsubsection{Biaxial Tensile Tests and Combined Tension-Com- pression Tests}

The nominal stress ratios chosen for the biaxial tensile tests were $\sigma_{\mathrm{N} x}: \sigma_{\mathrm{N} y}=1: 0,4: 1,2: 1,4: 3,1: 1,3: 4,1: 2$, $1: 4$ and $0: 1$ and those for the combined tension-compression tests were $\sigma_{\mathrm{N} x}: \sigma_{\mathrm{N} y}=-1: 2,-1: 1$ and $-2: 1$. The strain rates were $(0.9-3.9) \times 10^{-4} / \mathrm{s}$ for the biaxial tensile tests and $(1.2-9.9) \times 10^{-3} / \mathrm{s}$ for the combined tension-compression tests. The gauge area of the combined tensioncompression specimen (Fig. 1(c)) was fully covered with Teflon sheet using Vaseline in order to reduce friction between the specimen and the dies.

To evaluate the work hardening behavior of the test material under biaxial tension, the concept of a plastic work contour $^{23,24)}$ in the stress space was introduced. This was motivated by simulation of the metal forming, in which the flow stress modeled as the average behavior of a material over a deformation range is more important than determining the initial yield locus of the material. The method for the construction of plastic work contours is given as follows. A uniaxial tension test in the $\mathrm{RD}$ of the material $\left(\sigma_{x}: \sigma_{y}=\right.$ $1: 0)$ is first conducted, and the uniaxial true stress $\sigma_{0}$ and plastic work $W$ dissipated per unit volume are determined for particular values of the uniaxial logarithmic plastic strain $\varepsilon_{0}^{\mathrm{p}}$. Uniaxial tension tests in the TD of the material $\left(\sigma_{x}: \sigma_{y}=0: 1\right)$ and biaxial tension tests with the stress ratio $\sigma_{x}: \sigma_{y}$ held at specific proportions are also carried out. Finally, groups of stress points $\left(\sigma_{x}, \sigma_{y}\right)$ for which the same amount of plastic work $W$ is required, are plotted in the principal stress space to construct contours of plastic work corresponding to particular values of $\varepsilon_{0}^{\mathrm{p}}$. When $\varepsilon_{0}^{\mathrm{p}}$ is taken as sufficiently small, the corresponding work contour can be practically viewed as a yield locus.

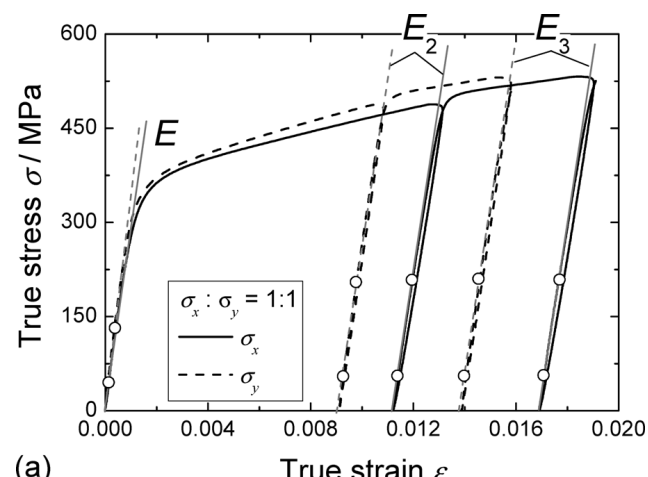

(a)

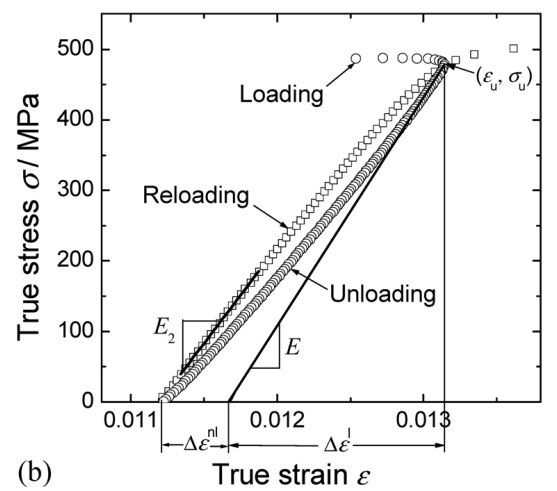

Fig. 4. (a) Typical biaxial stress-strain curves measured in an equi-biaxial loading-unloading test. $E, E_{2}$ and $E_{3}$ are the elastic moduli measured during the initial, second and third loadings, respectively. (b) A typical measured stress-strain curve during unloading and reloading. $\sigma_{\mathrm{u}}$ and $\varepsilon_{\mathrm{u}}$ are the stress and strain values at unloading, $\Delta \varepsilon^{\mathrm{nl}}$ is the nonlinear strain recovery, and $\Delta \varepsilon^{1}$ is the linear elastic strain recovery.

It should be noted that the offset plastic strain was not used for the definition of the yield locus, as has been customarily used by a number of other authors. ${ }^{25,26)}$ The materials under test are anisotropic; therefore, the plastic work definition of yielding, which has a definite physical meaning, appears to be more appropriate than the offset plastic strain definition, which is certainly equivalent to the former only for von Mises-type materials.

\subsubsection{Biaxial Loading-Unloading Tests}

The nominal stress ratios chosen for the uniaxial and biaxial loading-unloading tests were $\sigma_{\mathrm{N} x}: \sigma_{\mathrm{N} y}=1: 0,2: 1,1$ : $1,1: 2$ and $0: 1$. The stress ratios were kept constant in each test during loading and unloading. The strain rates during unloading were $(1-8) \times 10^{-4} / \mathrm{s}$.

Biaxial loading-unloading tests were performed as follows. As a first loading, the specimen was initially prestrained up to approximately $\varepsilon_{0}^{\mathrm{p}}=0.02$ and then unloaded with the same stress ratio as in loading. After confirming that $F_{x}$ and $F_{y}$ became zero, the specimen was further deformed up to a total equivalent plastic strain of $\varepsilon_{0}^{\mathrm{p}}=0.03$ (second loading). The specimen was then unloaded and finally reloaded up to fracture (third loading).

Figure 4(a) shows typical biaxial stress-strain curves measured in an equi-biaxial loading-unloading test $\left(\sigma_{x}\right.$ : $\left.\sigma_{y}=1: 1\right)$, where $E, E_{2}$ and $E_{3}$ are the slopes of the stressstrain curves in the elastic range measured for the initial, second and third loadings, respectively (henceforth simply referred to as elastic moduli). E, $E_{2}$ and $E_{3}$ were determined 
using the linear fitting function installed in Origin 7.5 software, which is based on a linear regression method. The range of linear fitting was taken to be from approximately $20 \mathrm{MPa}$ up to half of the apparent yield stress. For $\sigma_{x}: \sigma_{y}=$ $2: 1$ and $1: 2 E, E_{2}$ and $E_{3}$ were measured only in the maximum stress direction.

Figure 4(b) shows a typical measured stress-strain curve during unloading and reloading. The straight line in the figure indicates the elastic modulus $E$, as determined from the initial loading. The amounts of linear strain recovery $\Delta \varepsilon^{1}$, and the nonlinear (inelastic) strain recovery $\Delta \varepsilon^{\mathrm{nl}}$, were measured for each stress ratio, as shown in Fig. 4(b). The instantaneous tangent modulus during unloading $d \sigma / d \varepsilon$, simply referred to as the tangent modulus henceforth, was also measured and analyzed. $d \sigma / d \varepsilon$ was calculated using the least squares average for a set of 100 successive data points taken from the true stress-strain signals. Therefore, the measured value of $d \sigma / d \varepsilon$ for one measurement point approximately represents the average slope of the unloading stress-strain curve for a strain increment of $(6-8) \times 10^{-5}$.

\section{Results and Discussion}

\subsection{Comparison of Work Contours and Directions of Plastic Strain Rates with Those Predicted Using Conventional Yield Functions}

Figure 5 shows measured stress points, $\left(\sigma_{x}, \sigma_{y}\right)$, comprising contours of plastic work for particular values of $\varepsilon_{0}^{\mathrm{p}}$. The stress values were normalized by $\sigma_{0}$ corresponding to each $\varepsilon_{0}^{\mathrm{p}}$. Also depicted in the figure are the theoretical yield
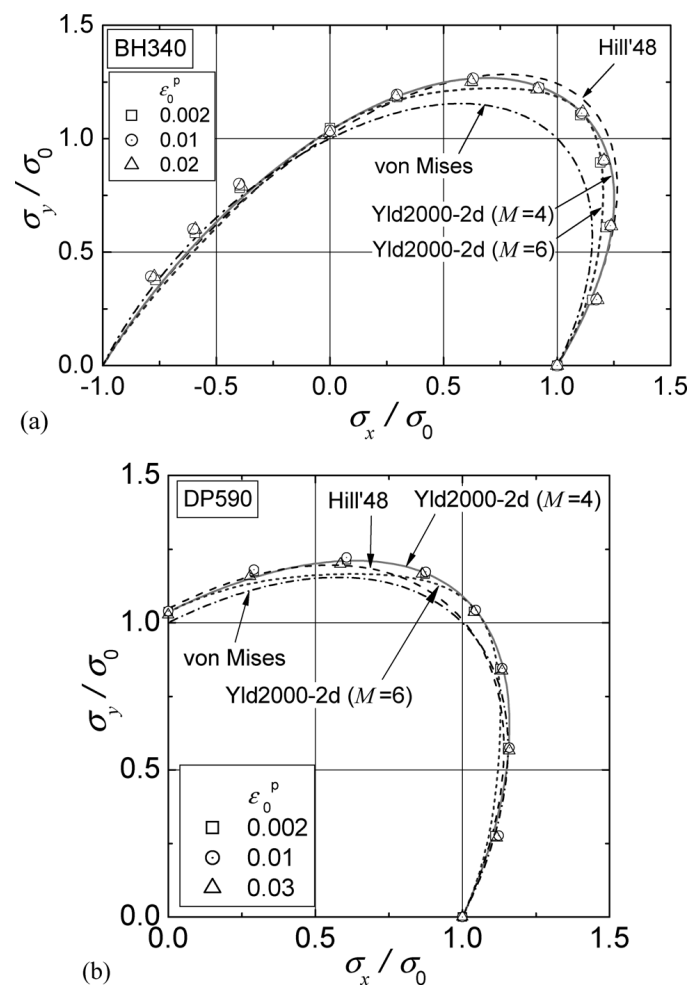

Fig. 5. Measured stress points comprising the contours of plastic work for $\varepsilon_{0}^{\mathrm{p}}=0.002,0.01$ and 0.02 , compared with the theoretical yield loci based on the von Mises, Hill's quadratic (Hill' 48) and the Yld2000-2d yield functions: (a) BH340 and (b) DP590. The stress values were normalized by $\sigma_{0}$ corresponding to each $\varepsilon_{0}^{\mathrm{p}}$. loci based on the von Mises, ${ }^{27)}$ Hill's quadratic (Hill' 48) ${ }^{28)}$ and the Yld2000-2d non-quadratic ${ }^{29)}$ yield functions. The anisotropic parameters of the Hill's quadratic yield function were determined using $\sigma_{0}, r_{0}$ and $r_{90}$, and those of the Yld2000-2d were determined using $\sigma_{0}, \sigma_{45}, \sigma_{90}, r_{0}, r_{45}, r_{90}$, $\sigma_{\mathrm{b}}$ and $r_{\mathrm{b}}$, where $\sigma_{\alpha}$ and $r_{\alpha}\left(\alpha=0,45\right.$ and $\left.90^{\circ}\right)$ are the flow stress and the $r$-value, respectively, measured for the uniaxial tensile test inclined by $\alpha$-degrees from the RD, and $\sigma_{\mathrm{b}}$ and $r_{\mathrm{b}}$ are the flow stress and the plastic strain rate ratio, $\left(d \varepsilon_{y} / d t\right) /\left(d \varepsilon_{x} / d t\right)$, respectively, at a given $\varepsilon_{0}^{\mathrm{p}}$ under equi-biaxial tension. As depicted in Figs. 5(a) and 5(b), the von Mises yield function underestimates the normalized work contours of both materials. The Hill's quadratic yield function overestimates the work contours of BH340 for stress ratios $\sigma_{x}: \sigma_{y}=3: 4,1: 1$ and $4: 3$, while the work contours of DP590 are only slightly underestimated for the same stress ratios. The Yld2000-2d yield function with an exponent of $M=4$ is generally in good agreement with the measured work contours for both materials.

Figure 6 shows a comparison between the measured directions of the plastic strain rates $\theta$ at $\varepsilon_{0}^{\mathrm{p}}=0.01$ and 0.02 for all stress ratios, and those of the local outward vectors normal to the theoretical yield loci, based on the von Mises, Hill's quadratic and the Yld2000-2d yield functions; note that the stress ratio is represented by the angle of the stress vector $\varphi$, in stress space. The experimental data points are generally in good agreement with those predicted using the Yld2000-2d yield function with an exponent of $M=4$ for both materials. This implies that the normality flow rule is well satisfied choosing the Yld2000-2d yield function with $M=4$ as the plastic potential for both materials.
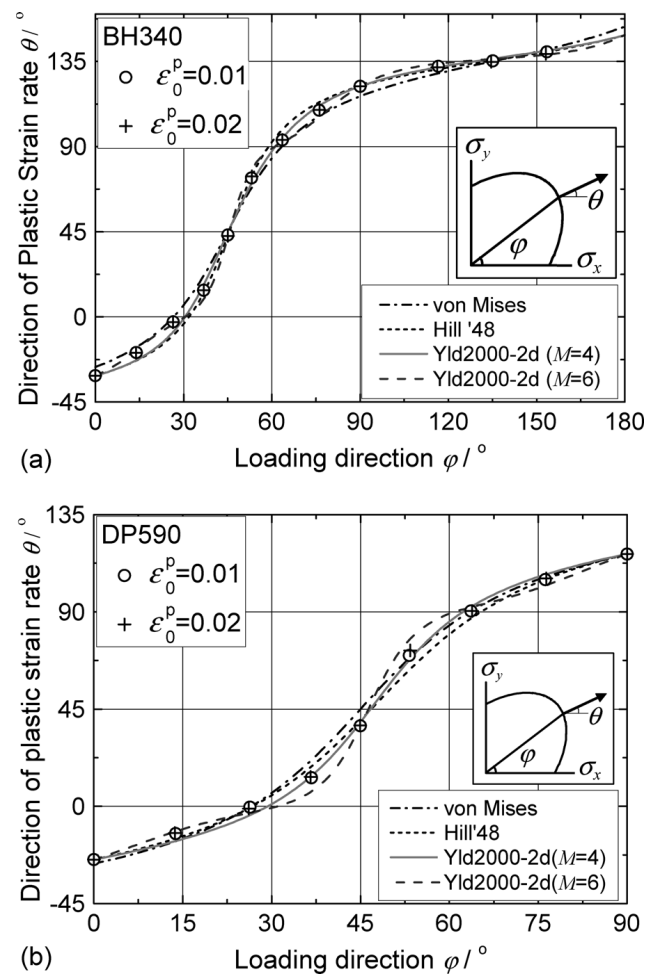

Fig. 6. Directions of plastic strain rates measured at $\varepsilon_{0}^{\mathrm{p}}=0.01$ and 0.02, compared with those calculated using the von Mises, Hill's quadratic (Hill' 48) and the Yld2000-2d yield functions: (a) BH340 and (b) DP590. 

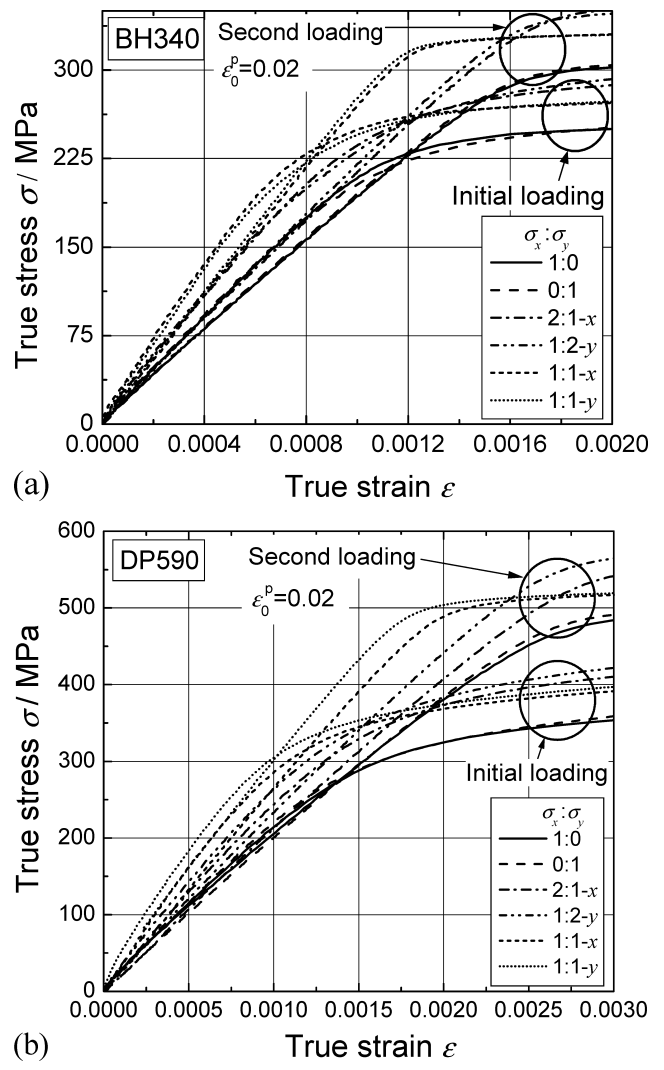

Fig. 7. Stress-strain curves in the maximum stress direction measured for the initial and second loading with different stress ratios: (a) BH340 and (b) DP590.

Table 2. Modulus of elasticity during the initial and two subsequent reloading stages.

\begin{tabular}{|c|c|c|c|c|c|}
\hline$\sigma_{x}: \sigma_{y}$ & $\begin{array}{c}E \\
/ \mathrm{GPa}\end{array}$ & $\begin{array}{c}E_{2}{ }^{*} \\
/ \mathrm{GPa}\end{array}$ & $\begin{array}{l}E_{3} * * \\
/ \mathrm{GPa}\end{array}$ & $\begin{array}{c}\frac{E-E_{2}}{E} \times 100 \\
/ \%\end{array}$ & $\frac{E-E_{3}}{E} \times 100$ \\
\hline \multicolumn{6}{|l|}{ BH340 } \\
\hline 1:0 & 219 & 190 & 189 & $13 \pm 3$ & $14 \pm 1$ \\
\hline $0: 1$ & 226 & 195 & 198 & $14 \pm 1$ & $12 \pm 3$ \\
\hline $2: 1-x$ & 253 & 210 & $x$ & $17 \pm 2$ & 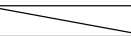 \\
\hline $1: 2-y$ & 264 & 221 & $\gamma$ & $16 \pm 3$ & \\
\hline $1: 1-x$ & 331 & 277 & 270 & $16 \pm 1$ & $18 \pm 3$ \\
\hline $1: 1-y$ & 324 & 283 & 276 & $13 \pm 2$ & $15 \pm 3$ \\
\hline \multicolumn{6}{|l|}{ DP590 } \\
\hline 1:0 & 213 & 189 & 193 & $11 \pm 1$ & $9 \pm 2$ \\
\hline $0: 1$ & 219 & 199 & 196 & $9 \pm 1$ & $11 \pm 3$ \\
\hline $2: 1-x$ & 255 & 212 & 204 & $17 \pm 3$ & $20 \pm 3$ \\
\hline $1: 2-y$ & 272 & 228 & 218 & $16 \pm 1$ & $20 \pm 1$ \\
\hline $1: 1-x$ & 334 & 274 & 268 & $18 \pm 3$ & $20 \pm 3$ \\
\hline $1: 1-y$ & 335 & 292 & 285 & $13 \pm 2$ & $15 \pm 1$ \\
\hline
\end{tabular}

* $E_{2}$ : Modulus of elasticity after an equivalent plastic prestrain of $\varepsilon_{0}^{\mathrm{p}} \cong 0.02$

${ }^{* *} E_{3}$ : Modulus of elasticity after an equivalent plastic prestrain of $\varepsilon_{0}^{\mathrm{p}} \cong 0.03$

\subsection{Effect of Prestrain on the Elastic Modulus}

Figure 7 shows the measured true stress-strain curves for initial and subsequent reloading. It is clear that for a given stress ratio, the slope of the curve in the elastic range, i.e., the elastic modulus, is lower for the subsequent reloading than that for the initial loading.

Table 2 shows the results of the measured initial and subsequent elastic moduli for each stress ratio. Table 2 does not include the data for $E_{3}$ of BH340 for $\sigma_{x}: \sigma_{y}=2: 1-x$ and $1: 2-y$, because the specimens fractured prior to reaching $\varepsilon_{0}^{\mathrm{p}}=0.03$. It was found that $E_{2}$ and $E_{3}$ were 10 to $20 \%$ lower than the initial elasticity modulus $E$, under the stress

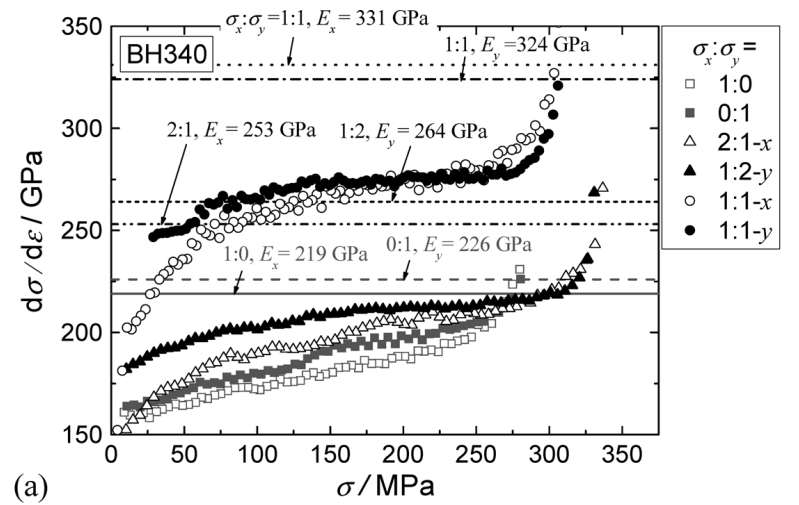

(a)

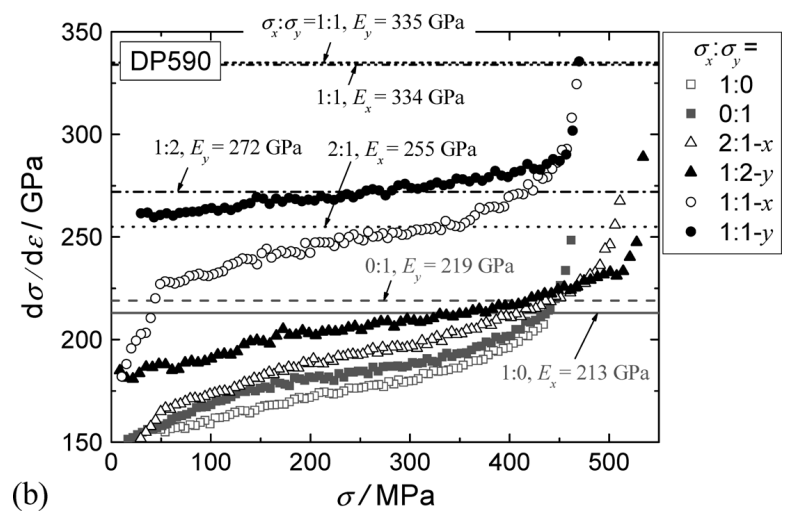

Fig. 8. Change in the tangent modulus $d \sigma / d \varepsilon$, for the maximum stress direction with decreasing true stress under uniaxial and biaxial unloading after an equivalent plastic strain of $\varepsilon_{0}^{\mathrm{p}}=0.02$ : (a) BH340 and (b) DP590.

states considered in this study, and there was no difference between $E_{2}$ and $E_{3}$, which were within the scatter of data.

\subsection{Tangent Modulus during Unloading}

Figure 8 shows the behavior of the tangent modulus $d \sigma /$ $d \varepsilon$, during unloading. Each curve was obtained by averaging the experimental data measured for three specimens. For comparison, $E$ in the maximum stress direction for each stress ratio is also included in the figure as a horizontal line.

For better comparison of the behavior of the tangent modulus between different stress ratios, the data in Fig. 8 were re-plotted in Fig. 9 to show the relationship between $(d \sigma / d \varepsilon) / E$ and $\sigma / \sigma_{\mathrm{u}}$. It is clear that the value of $d \sigma / d \varepsilon$ at the commencement of unloading is nearly the same as the initial elastic modulus for all stress ratios, while $d \sigma / d \varepsilon$ decreases with $\sigma$.

Cleveland and Ghosh ${ }^{10)}$ suggested that the general trend of uniaxial unloading stress-strain curves can be categorized into three stages:

Stage I: The tangent modulus decreases rapidly at the beginning of unloading.

Stage II: The rate of decreasing tangent modulus becomes almost constant.

Stage III: The tangent modulus decreases rapidly once again with decreasing stress.

In Fig. 9, stages I and II are clearly observed for all stress ratios. Stage III is also clearly observed for $\sigma_{x}: \sigma_{y}=1: 1-x$ and $2: 1-x$ for both materials, but is not so obvious for other stress ratios.

Table 3 tabulates the measured nonlinear strain recovery $\Delta \varepsilon^{\mathrm{nl}}$, and the linear strain recovery, $\Delta \varepsilon^{\mathrm{l}}$. The nonlinear 

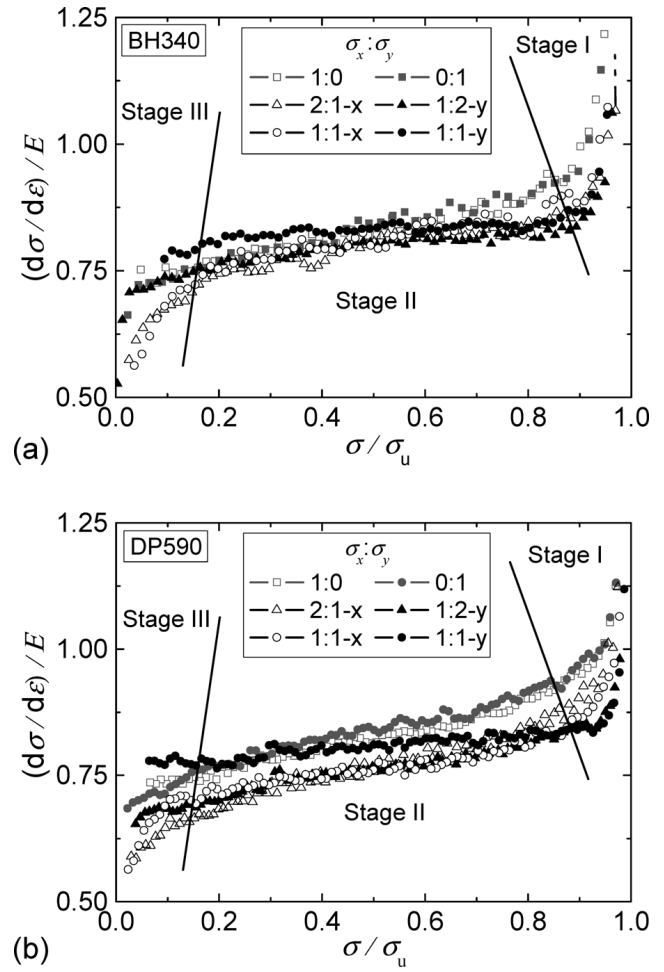

Fig. 9. Change in the non-dimensional tangent modulus for the maximum stress direction with decrease in the non-dimensional true stress under uniaxial and biaxial unloading after an equivalent plastic strain of $\varepsilon_{0}^{\mathrm{p}}=0.02$.

Table 3. Measured values of the nonlinear strain recovery $\Delta \varepsilon^{\mathrm{nl}}$, and the linear strain recovery, $\Delta \varepsilon^{1}$.

\begin{tabular}{|l|c|c|c|}
\hline$\sigma_{x}: \sigma_{y}$ & $\Delta \varepsilon^{1}$ & $\Delta \varepsilon^{\mathrm{nl}}$ & $\frac{\Delta \varepsilon^{\mathrm{nl}}}{\Delta \varepsilon^{1}} \times 100 / \%$ \\
\hline \multicolumn{3}{|l|}{ Material: $\mathrm{BH} 340$} \\
\hline $1: 0$ & 0.0013 & 0.00024 & 18 \\
\hline $0: 1$ & 0.0013 & 0.00025 & 19 \\
\hline $2: 1-x$ & 0.0014 & 0.00037 & 27 \\
\hline $1: 2-y$ & 0.0013 & 0.00033 & 26 \\
\hline $1: 1-x$ & 0.0009 & 0.00023 & 24 \\
\hline $1: 1-y$ & 0.0010 & 0.00016 & 16 \\
\hline Material: D5590 \\
\hline $1: 0$ & 0.0022 & 0.00042 & 19 \\
\hline $0: 1$ & 0.0021 & 0.00045 & 21 \\
\hline $2: 1-x$ & 0.0021 & 0.00064 & 31 \\
\hline $1: 2-y$ & 0.0020 & 0.00060 & 30 \\
\hline $1: 1-x$ & 0.0014 & 0.00050 & 35 \\
\hline $1: 1-y$ & 0.0014 & 0.00029 & 20 \\
\hline
\end{tabular}

strain recovery as a percentage of the elastic strain recovery $\Delta \varepsilon^{\mathrm{nl}} / \Delta \varepsilon^{1}$, is slightly larger for the biaxial case than the uniaxial case; i.e., approximately $25 \%$ for BH340 and $30 \%$ for DP590, while under uniaxial unloading it was approximately $20 \%$ for both materials. The results of elastic strain recovery for the uniaxial experiments are in good agreement with the results obtained for a high strength steel as reported by Cleveland and Ghosh, ${ }^{10)}$ which showed that the net unloading strain recovery (linear elastic and non-linear elastic) exceeded the expected linear elastic strain recovery by approximately $19 \%$.
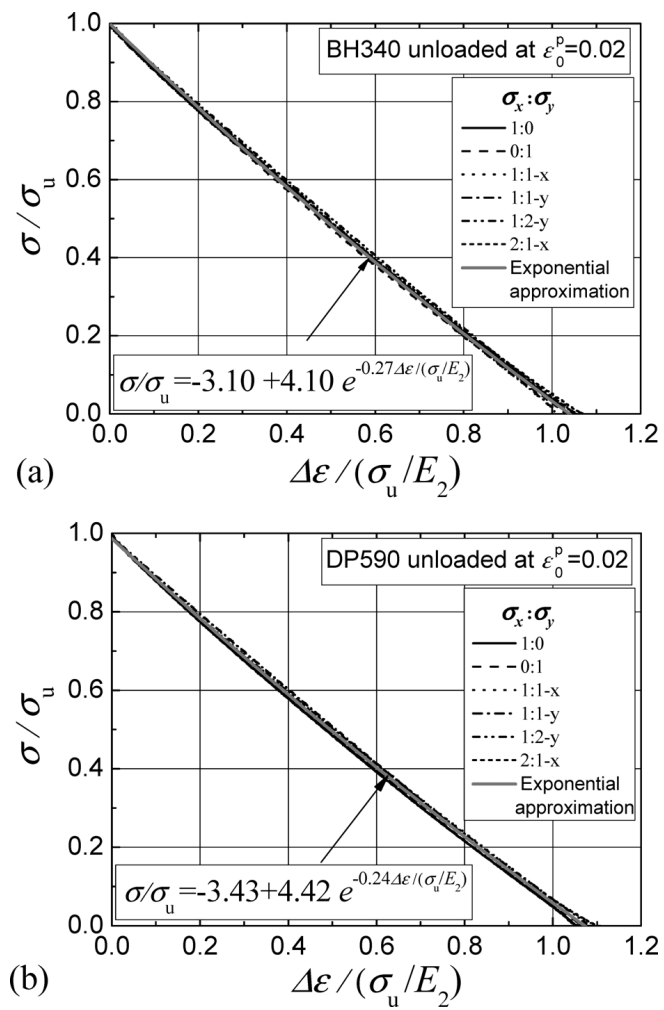

Fig. 10. Relationship between the non-dimensional true stress and the recovered strain normalized by $\sigma_{\mathrm{u}} / E_{2}$ during uniaxial and biaxial unloading after an equivalent plastic strain of $\varepsilon_{0}^{\mathrm{p}}=0.02$ : (a) BH340 and (b) DP590.

\section{Approximating the Unloading Behavior Using an Exponential Function}

Figure 10 shows the normalized unloading stress $\sigma / \sigma_{\mathrm{u}}$, versus the normalized recovered strain $\Delta \varepsilon /\left(\sigma_{u} / E_{2}\right)$, after $2 \%$ equivalent prestrain for all stress states. All of the $\left(\sigma / \sigma_{\mathrm{u}}\right)-\Delta \varepsilon /\left(\sigma_{\mathrm{u}} / E_{2}\right)$ curves nearly fall on a single curve and are independent of the stress ratio. The $\left(\sigma / \sigma_{\mathrm{u}}\right)-\Delta \varepsilon /\left(\sigma_{\mathrm{u}} / E_{2}\right)$ curves can be approximated by the following analytical functions:

$$
\frac{\sigma}{\sigma_{\mathrm{u}}}=-3.10+4.10 \exp \left\{-0.27 \frac{\Delta \varepsilon}{\sigma_{\mathrm{u}} / E_{2}}\right\} \text { for BH340 }
$$

$$
\frac{\sigma}{\sigma_{\mathrm{u}}}=-3.43+4.42 \exp \left\{-0.24 \frac{\Delta \varepsilon}{\sigma_{\mathrm{u}} / E_{2}}\right\} \text { for DP590 }
$$

These equations will be useful for taking into account the nonlinearity of the unloading stress-strain curves in springback simulations.

Figure 11 shows the calculated $(d \sigma / d \varepsilon)-\sigma$ relations based on Eqs. (1) and (2) with the experimentally observed results shown in Fig. 8. The calculated results are generally in fair agreement with the experimental data during stage II, where $d \sigma / d \varepsilon$ is almost constantly decreasing. 

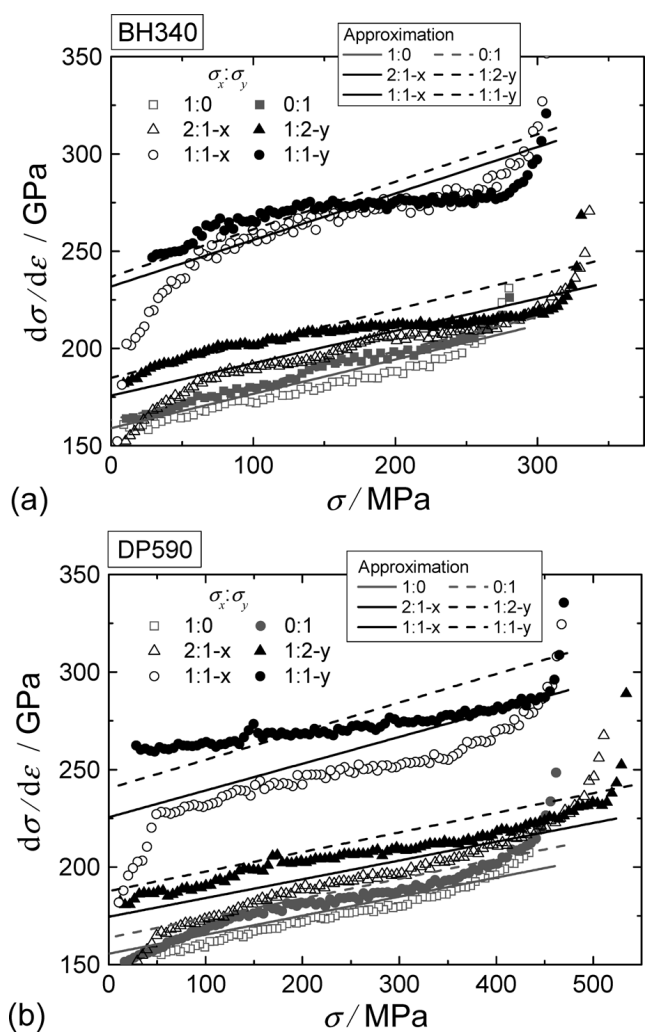

Fig. 11. Measured tangent moduli compared with those calculated using (a) Eq. (1) for BH340 and (b) Eq. (2) for DP590.

\section{Conclusions}

The work hardening behavior and unloading stress-strain relations for two types of steel alloys, BH340 and DP590, were precisely measured under uniaxial and biaxial stress states. The following conclusions were obtained.

(1) The Yld2000-2d non-quadratic yield function with an exponent of 4 is an appropriate material model for reproducing the anisotropic plastic deformation behavior of the examined test materials.

(2) For the stress states considered in this study, the modulus of elasticity at the second loading $E_{2}$, after a prestrain of $\varepsilon_{0}^{\mathrm{p}} \approx 0.02$, was 10 to $20 \%$ lower than the initial elasticity modulus, $E$.

(3) The inelastic strain recovery, as a percentage of elastic strain recovery for the biaxial unloading, was approximately $25 \%$ for BH340 and $30 \%$ for DP590, while under uniaxial unloading it was approximately $20 \%$ for both materials.

(4) $\left(\sigma / \sigma_{\mathrm{u}}\right)-\Delta \varepsilon /\left(\sigma_{\mathrm{u}} / E_{2}\right)$ curves measured during unloading of the uniaxially and biaxially prestrained test materials almost fall on a single curve; they are almost independent of the amount of prestrain and the stress ratio. Therefore, the analytical expressions of the $\left(\sigma / \sigma_{\mathrm{u}}\right)-\Delta \varepsilon /\left(\sigma_{\mathrm{u}} / E_{2}\right)$ curves (Eqs. (1) and (2)) will be useful for taking into account the nonlinearity of the unloading stress-strain behaviors in springback simulations.

\section{Acknowledgement}

The authors wish to acknowledge the help of Mr. Satoshi Shirakami, who improved the software program for controlling the biaxial tensile testing machine used in this study.

\section{REFERENCES}

1) T. Kuwabara, N. Seki and S. Takahashi: J. Jpn. Soc. Technol. Plast., 39 (1998), 1081.

2) T. Kuwabara, S. Ikeda and Y. Asano: Proc. 8th Int. Conf. on Numerical Methods in Industrial Forming Processes, American Institute of Physics, New York, (2004), 887.

3) T. Kuwabara: Proc. Int. Symp. Automotive Sheet Metal Forming, Tata McGraw-Hill, New Delhi, (2008), 19.

4) F. Yoshida, T. Uemori and K. Fujiwara: Int. J. Plast., 18 (2002), 633.

5) K. Chung, M.-G. Lee, D. Kim, C. Kim, M. L. Wenner and F. Barlat: Int. J. Plast., 21 (2005), 861.

6) T. Kuwabara, R. Saito, T. Hirano and N. Oohashi: Tetsu-to-Hagané, 95 (2009), 732.

7) T. Kuwabara: Int. J. Plast., 23 (2007), 385.

8) A. Hannon and P. Tiernan: J. Mater. Proc. Technol., 198 (2008), 1.

9) S. Shima and M. Yang: J. Soc. Mater. Sci. Jpn., 44 (1995), 578.

10) R. M. Cleveland and A. K. Ghosh: Int. J. Plast., 18 (2002), 769.

11) M. Yang: J. Jpn. Soc. Technol. Plast., 45 (2004), 991.

12) T. Iwata, H. Tsutamori, N. Suzuki, H. Ishihara, M. Masao and M. Gotoh: J. Jpn. Soc. Technol. Plast., 43 (2002), 1178.

13) T. Kuwabara, S. Ikeda and T. Kuroda: J. Mater. Proc. Technol., 80-81 (1998), 517.

14) T. Kuwabara, M. Kuroda, V. Tvergaard and K. Nomura: Acta Mater, 48 (2000), 2071.

15) T. Kuwabara, A. V. Bael and E. Iizuka: Acta Mater, 50 (2002), 3717.

16) S. Ikeda and T. Kuwabara: Tetsu-to-Hagané, 90 (2004), 1016.

17) K. Hashimoto, T. Kuwabara, E. Iizuka and J. W. Yoon: J. Jpn. Soc. Technol. Plast., 50 (2009), 925.

18) T. Kuwabara, M. Umemura, K. Yoshida, M. Kuroda, S. Hirano and Y. Kikuta: J. Jpn. Inst. Light Met., 56 (2006), 323.

19) S. Murakoso and T. Kuwabara: J. Solid Mech. Mater. Eng. (to be published)

20) M. Ishiki, T. Kuwabara, M. Yamaguchi, Y. Maeda, Y. Hayashida and Y. Itsumi: Trans. Jpn. Soc. Mech. Eng. (A), 75 (2009), 491.

21) T. Kuwabara, Y. Horiuchi, N. Uema and J. Ziegelheimova: J. Jpn. Soc. Technol. Plast., 48 (2007), 630.

22) E. Shiratori and K. Ikegami: J. Mech. Phys. Solids, 16 (1968), 373.

23) R. Hill and J. W. Hutchinson: J. Appl. Mech., 59 (1992), S1.

24) R. Hill, S. S. Hecker and M. G Stout: Int. J. Solids Structures, 31 (1994), 2999.

25) S. S. Hecker: Constitutive Equations in Viscoplasticity: Computational and Engineering Aspects, ed. by J. A. Stricklin and K. H. Saczalski, ASME, New York, (1976), 1.

26) A. Phillips: Int. J. Plast., 2 (1986), 315.

27) R. Von Mises: Göttingen Nachrichten Math.-Phys. Klasse, (1913), 582.

28) R. Hill: Proc. R. Soc. (London), A193 (1948), 281.

29) F. Barlat, J. C. Brem, J. W. Yoon, K. Chung, R. E. Dick, D. J. Lege, F. Pourboghrat, S. H. Choi and E. Chu: Int. J. Plast., 19 (2003), 1297. 